\begin{tabular}{|c|c|c|}
\hline \multirow{3}{*}{$\begin{array}{r}\text { Case Reports in } \\
\text { Gastroenterology }\end{array}$} & \multirow{2}{*}{\multicolumn{2}{|c|}{ Case Rep Gastroenterol 2013;7:358-362 }} \\
\hline & & \\
\hline & $\begin{array}{l}\text { DOI: 10.1159/000354972 } \\
\text { Published online: August 24, } 2013\end{array}$ & $\begin{array}{l}\text { ○ } 2013 \text { S. Karger AG, Basel } \\
\text { 1662-0631/13/0072-0358 } \$ 38.00 / 0 \\
\text { www.karger.com/crg }\end{array}$ \\
\hline & \multicolumn{2}{|c|}{$\begin{array}{l}\text { This is an Open Access article licensed under the terms of the Creative Commons } \\
\text { Attribution-NonCommercial } 3.0 \text { Unported license (CC BY-NC) (www.karger.com/OA } \\
\text { license), applicable to the online version of the article only. Distribution permitted for non } \\
\text { commercial purposes only. }\end{array}$} \\
\hline
\end{tabular}

\title{
Familial Adenomatous Polyposis and Crohn's Disease in One Patient: Dilemmas and Concerns
}

\author{
Catarina Fidalgo ${ }^{a}$ Sara Ferreira ${ }^{a, b}$ Isadora Rosa $a^{a, b}$ \\ Susana Mão de Ferro ${ }^{a}$ António Dias Pereira ${ }^{a}$ \\ ${ }^{a}$ Gastroenterology Department and ${ }^{b}$ Family Risk Clinic, Instituto Português de Oncologia \\ de Lisboa Francisco Gentil, E.P.E., Lisbon, Portugal
}

\section{Key Words}

Familial adenomatous polyposis · Crohn's disease · Capsule endoscopy

\begin{abstract}
Familial adenomatous polyposis (FAP) and Crohn's disease (CD) are two entities with no known etiologic or physiopathogenic relation. The rarity of the former makes the coincidence of both diagnoses in one patient very unlikely. Nevertheless, management in such cases can be puzzling as surgical options must be considered, and immunosuppression/immunomodulation is set in a territory of accelerated carcinogenesis. We report the case of a 29-year-old male with a diagnosis of FAP since adolescence, already submitted to prophylactic proctocolectomy, presenting with anemia and bloody diarrhea, revealing small bowel CD. This case allows for a rich discussion of the clinical dilemmas presenting when FAP and CD are diagnosed in the same patient and for a deep analysis of the concerns inherent to the available therapeutic options.

(c) 2013 S. Karger AG, Basel
\end{abstract}

\section{Introduction}

Familial adenomatous polyposis (FAP) is an autosomal dominant inherited disease that dictates development of colorectal adenocarcinoma in virtually all affected individuals by the age of 50, unless prophylactic proctocolectomy is performed timely. Even after this mutilating surgery, patients bear a significantly increased risk of duodenal adenocarcinoma (4-12\% lifetime incidence) and a risk of small bowel carcinoma 13 times greater than that of the general population [1]. Early diagnosis of FAP and proctocolectomy allow extended survival, and concomitance with other diseases may appear as a clinical challenge.

Catarina Andrade Fidalgo

Serviço de Gastrenterologia

Instituto Português de Oncologia de Lisboa Francisco Gentil, E.P.E.

Rua Professor Lima Basto, PT-1099-023 Lisbon (Portugal)

E-Mail catarinafidalgo@inbox.com 
Fidalgo et al.: Familial Adenomatous Polyposis and Crohn's Disease in One Patient: Dilemmas and Concerns

Crohn's disease (CD) is a chronic inflammatory bowel disease of unknown etiology that can affect any segment of the digestive tract. Immunosuppressants and immunomodulators such as anti-tumor necrosis factor (anti-TNF) agents are the mainstay of therapy for inducing and maintaining remission in moderate to severe disease. Despite advances in medical therapy, the majority of patients will need at least one surgery during their life, and issues such as permanent stoma or short bowel syndrome are not out of the horizon.

The case we report illustrates the extremely rare association of FAP and CD in the same patient, with obvious challenges in diagnosis, management and cancer surveillance.

\section{Case Report}

A 29-year-old man presents with bloody diarrhea, progressive asthenia and weight loss ( $8 \%$ of his usual weight in 6 months). Physical examination was unremarkable and laboratory tests showed iron deficiency anemia (hemoglobin $8.5 \mathrm{~g} / \mathrm{dl}$, mean corpuscular volume $72 \mathrm{fl}$, serum iron $8 \mu \mathrm{g} / \mathrm{dl}$ and serum ferritin $5 \mathrm{ng} / \mathrm{ml}$ ). He was a smoker of 10 cigarettes per day.

The patient was followed in our family cancer risk clinic because he belonged to a family with FAP. At the age of 16 colonic phenotype became evident and genetic testing was performed at age 18. Prophylactic proctocolectomy with J-ileal pouch and ileo-anal anastomosis was performed when he was 26 years old and he maintained sphincteric tone with good continence and about 4 bowel movements per day. Annual physical examination, laboratory screening and endoscopic evaluation of the pouch was performed as well as upper gastrointestinal endoscopy as dictated by the Spigelman score (last upper gastrointestinal endoscopy performed 3 months before symptoms).

One year before bloody diarrhea and weight loss were noted, multiple ulcers were seen on a routine pouch evaluation. At that time he was completely asymptomatic, hemoglobin levels were normal, and he mentioned a 7-day course of nonsteroidal anti-inflammatory drugs for dental pain. Biopsies showed subacute inflammation. Nonsteroidal anti-inflammatory drugs enteropathy was assumed at that time.

Investigation consisted of upper gastrointestinal endoscopy with findings of mild esophagitis and duodenal polyposis (Spigelman II), and pouch endoscopy showed no abnormal features. Stool cultures were negative. Small bowel capsule endoscopy showed multiple deep ulcers, some of them $>2 \mathrm{~cm}$ long, and a hyperemic and congestive surrounding mucosa (fig. 1). Ileoscopy up to $60 \mathrm{~cm}$ from the anal verge was performed and multiple biopsies were taken from the ulcerated surface (fig. 2). Histology showed ulceration, regenerative changes, inflammation with lymphoid follicle formation and numerous polymorphonuclear cells infiltrating the submucosa. CD was assumed. MRI enterography showed no abnormal findings other than mucosal uptake in the jejunum and ileum.

We considered him to be a high-risk patient as he was a young smoker, with severe small bowel involvement from CD including the upper gastrointestinal tract (jejunum), already submitted to small bowel surgery (ileal pouch). After the mandatory viral serology tests and latent tuberculosis screening, $60 \mathrm{mg}$ of oral prednisolone was started, with slow tapering during 12 weeks, while azathioprine was escalated up to $2.5 \mathrm{mg} / \mathrm{kg}$. Iron supplementation was started. One year after diagnosis of CD the patient is symptom-free, has gained back $8 \mathrm{~kg}$ and has a normal hemoglobin level with replenished iron reserve. 
Fidalgo et al.: Familial Adenomatous Polyposis and Crohn's Disease in One Patient: Dilemmas and Concerns

\section{Discussion}

The prevalence of FAP in Portugal is thought to be around 1/7,500 and that of CD is $1 / 1,667$. Assuming that there is no causal relation between FAP and CD, the coexistence of these two entities in the same patient is statistically a rarity. Nevertheless, there are to our knowledge three case reports of concomitant FAP and CD [1-3]. The association of FAP and $\mathrm{CD}$ raises many concerns that we will try to discuss below.

\section{$C D$ and FAP: Surgical Aspects?}

If $\mathrm{CD}$ is known before surgery for FAP, the most important aspect is to completely assess the small bowel before surgery, in order to decide whether it is wise to proceed to proctocolectomy with ileal pouch. This should be done by CT or MRI enterography and capsule endoscopy if no stenotic segments are described. A patient with CD may need small bowel surgery during his lifetime, and concerns about short bowel syndrome could make an ileostomy more advisable. We think that surgical decisions must be made on a case to case basis, taking into account CD risk features, namely young age at presentation, smoker status, phenotype, upper or extensive small bowel affection and difficulty to achieve and maintain remission with medical therapy. Decisions must be shared with the surgeon and obviously with the patient, as permanent stoma means a serious quality of life impairment. If the CD diagnosis is only made intraoperatively, ileostomy would be the best option at least until CD is properly characterized. In the case described above, $\mathrm{CD}$ was diagnosed many years after FAP had been discovered and 2 years after prophylactic proctocolectomy with J-ileal pouch had been performed. This sequence of events makes the need to medically control CD vital in order to avoid further small bowel surgery. Family cancer risk clinics may represent a biased setting, as annual clinical evaluations and routine pouchoscopy offer the opportunity to diagnose otherwise subclinical disease. In these cases, CD with ileal involvement can be mistaken for pouchitis [4], with a delay in diagnosis, although it is known that pouchitis is very rare when the surgery is performed for FAP, and the threshold for alternative diagnosis should be low.

\section{Immunosuppression/Modulation in FAP Patients: A Risk Worth Taking?}

FAP is a hereditary high penetrance disease, with an autosomal dominant pattern, that dictates an increased cancer risk. Even after prophylactic proctocolectomy, FAP patients have an increased risk of extracolonic malignancy, namely duodenal cancer (4-12\% lifetime risk), thyroid cancer ( $2-3 \%$ lifetime risk) and medulloblastoma ( $<1 \%$ lifetime risk). The risk of small bowel cancer is also increased, although this disease remains rare [5].

Immunosuppression with azathioprine is considered the standard medical therapy for maintaining remission in moderate to severe CD [6]. Thiopurine analogues have been used in CD for more than 40 years. Up to date it is known that there is a 4-fold increase in the risk of lymphoma in patients treated with azathioprine [7] and a 5-fold increase in the risk of nonmelanoma skin cancer [8]. There is no association between thiopurine analogues and FAP-related cancers, namely small bowel cancer risk increase. In fact, thiopurines might even reduce the risk of colorectal cancer, as recently described in patients with inflammatory bowel disease, possibly by reducing inflammation [9]. Considering that carcinogenesis through APC loss is the most common pathway to sporadic colorectal cancer and that the cumulative experience with thiopurines has never shown an increase in the risk for this malignancy, we feel there is no reason to exclude this therapeutic option in FAP patients. Another option to induce and maintain remission in these patients is immunomodulation 
Fidalgo et al.: Familial Adenomatous Polyposis and Crohn's Disease in One Patient: Dilemmas and Concerns

with anti-TNF agents, but the risk of malignancy with these newer agents remains an unanswered issue.

\section{Small Bowel Cancer Risk: Is Surveillance Justified?}

Small bowel adenocarcinoma is very rare overall [10]. Few conditions increase this risk, including both FAP and CD. Small bowel cancer (distal to the ligament of Treitz) has rarely been reported in FAP patients and current guidelines state that there is no evidence supporting routine surveillance. Further studies are needed to know whether routine video capsule or MRI enterography are justified [11]. On the other hand, CD definitely increases small bowel cancer risk. The cumulative risk of small bowel adenocarcinoma seems to be around $2.2 \%$ at 25 years of disease, with ileal predominance. The risk is thought to be related to disease extension and duration. Routine small bowel surveillance is not recommended apart from disease assessment. It can only be speculated whether small bowel cancer risk is cumulative, synergistic or decreased in patients with both FAP and CD. It seems reasonable to try to reduce ongoing inflammation with medical therapy for CD and to have a low threshold to investigate unclear complaints. We feel there is no reason to adopt a routine screening protocol with enterography or enteroscopy.

\section{References}

1 Fukushima K, Funayama Y, Shibata C, et al: Familial adenomatous polyposis complicated with Crohn's disease. Int J Colorectal Dis 2006;21:730-731.

-2 Gentile N, Kane S: Familial adenomatous polyposis, suspected HNPCC, and Crohn's disease: two cases. Inflamm Bowel Dis 2012;18:E1398.

-3 Brignola C, Belloli C, De Simone G, et al: Familial adenomatous polyposis and inflammatory bowel disease associated in to kindreds. Dig Dis Sci 1995;40:402-405.

4 Navaneethan U, Shen B: Secondary pouchitis: those with identifiable etiopathogenic or triggering factors. Am J Gastroenterol 2010;105:51-64.

5 Bisgaard ML, Fenger K, Bülow S, et al: Familial adenomatous polyposis (FAP): frequency, penetrance, and mutation rate. Hum Mutat 1994;3:121-125.

-6 Prefontaine E, Macdonald JK, Sutherland LR: Azathioprine or 6-mercaptopurine for induction of remission in Crohn's disease. Cochrane Database Syst Rev 2010;6:CD000545.

7 Kandiel A, Fraser AG, Korelitz BI, et al: Increased risk of lymphoma among inflammatory bowel disease patients treated with azathioprine and 6-mercaptopurine. Gut 2005;54:1121-1125.

-8 Peyrin-Biroulet L, Khosrotehrani K, Carrat F, et al: Increased risk for nonmelanoma skin cancers in patients who receive thiopurines for inflammatory bowel disease. Gastroenterology 2011;141:1621-1628.e1-5.

-9 van Schaik FD, van Oijen MG, Smeets HM, et al: Thiopurines prevent advanced colorectal neoplasia in patients with inflammatory bowel disease. Gut 2012;61:235-240.

10 Siegel R, Naishadham D, Jemal A: Cancer statistics, 2012. CA Cancer J Clin 2012;62:10-29.

11 Vasen HF, Möslein G, Alonso A, et al: Guidelines for the clinical management of familial adenomatous polyposis (FAP). Gut 2008;57:704-713. 
Fidalgo et al:: Familial Adenomatous Polyposis and Crohn's Disease in One Patient: Dilemmas and Concerns

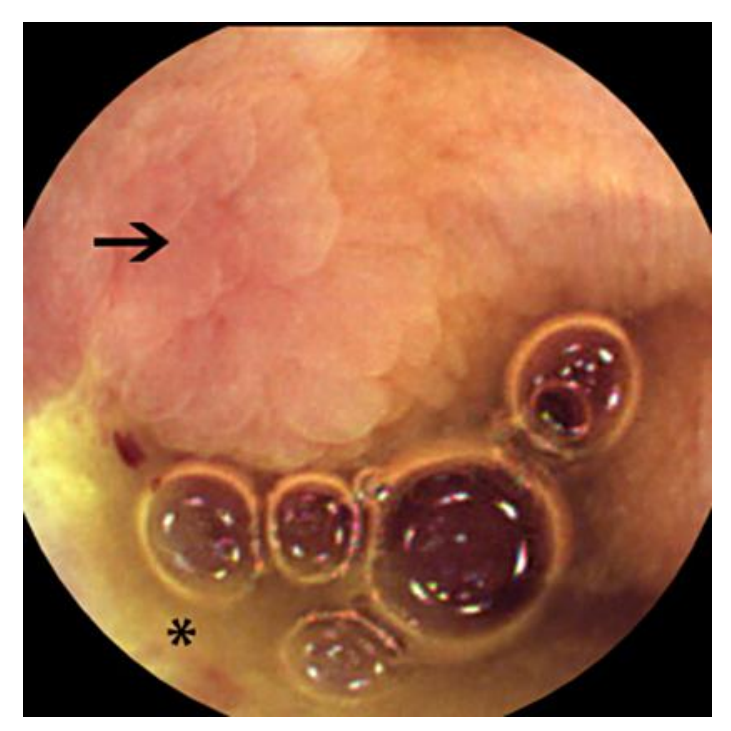

Fig. 1. Capsule endoscopy image. To evaluate small bowel involvement, capsule endoscopy was performed, showing multiple deep ulcers. In this picture the border of a long, deep ileal ulcer is shown (asterisk), with elevated, hyperemic borders (arrow).

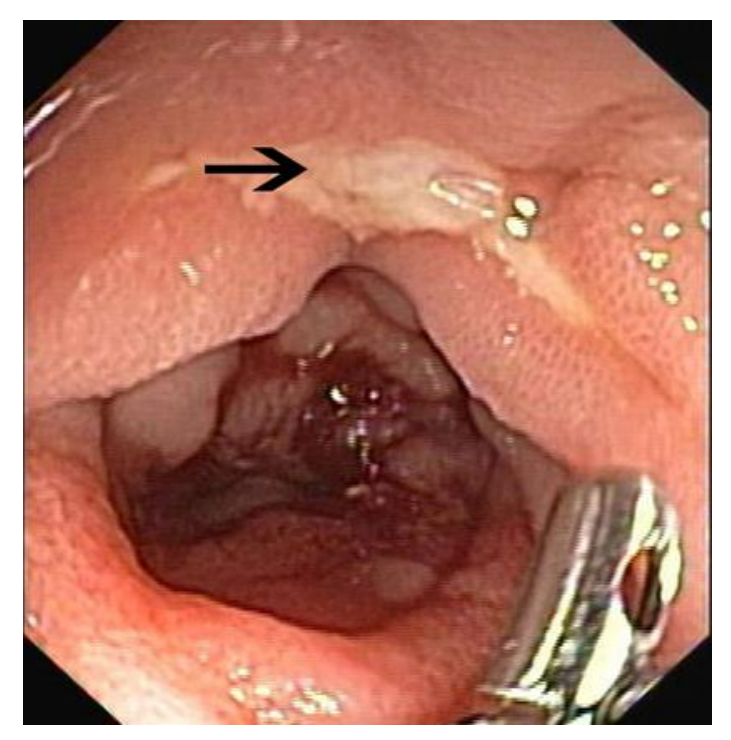

Fig. 2. Ileoscopy image. The presence of an ileal pouch allowed deep ileoscopy using a colonoscope, and multiple biopsies were taken from ileal ulcers (arrow) and the surrounding mucosa for histological analysis. This image shows an 8-mm-long, clean-based ileal ulcer. 